\title{
Epigenetic variation in Arabidopsis disease resistance
}

\author{
Trevor L. Stokes, Barbara N. Kunkel, and Eric J. Richards ${ }^{1}$ \\ Department of Biology, Washington University, St. Louis, Missouri 63130, USA
}

\begin{abstract}
Plant pathogen resistance is mediated by a large repertoire of resistance $(R)$ genes, which are often clustered in the genome and show a high degree of genetic variation. Here, we show that an Arabidopsis thaliana R-gene cluster is also subject to epigenetic variation. We describe a heritable but metastable epigenetic variant bal that overexpresses the $R$-like gene At4g16890 from a gene cluster on Chromosome 4. The bal variant and Arabidopsis transgenics overexpressing the At4g16890 gene are dwarfed and constitutively activate the salicylic acid (SA)-dependent defense response pathway. Overexpression of a related $R$-like gene also occurs in the ssi1 (suppressor of $\underline{S} A$ insensitivity $\underline{1}$ ) background, suggesting that ssi1 is mechanistically related to bal.
\end{abstract}

[Key Words: Epigenetics; cytosine methylation; resistance genes; bal; DDM1; Arabidopsis]

Received October 5, 2001; revised version accepted November 26, 2001.

Epigenetic variation is often overlooked as a source of phenotypic variation for natural or artificial selection. Variation in epigenetic information, encoded at the chromatin level rather than the nucleotide sequence level, is commonly thought to be transient and unlikely to underlie stable changes in phenotype. There is considerable evidence, however, that epigenetic changes, particularly those due to alterations in DNA methylation, can be inherited through meiosis and mimic traditional mutations.

Some of the earliest recognized heritable epigenetic alleles involve transposons whose differential DNA methylation and chromatin structure affect the expression of neighboring genes (McClintock 1951; Martienssen et al. 1990; Martienssen and Baron 1994; Fedoroff et al. 1995). Another classic example of epigenetic inheritance is paramutation, wherein interactions between alleles cause chromatin-mediated heritable changes in gene expression (Kermicle et al. 1995; Hollick et al. 1997; Walker 1998). Several groups have recently reported defects in flower development caused by heritable epigenetic alleles (epialleles) associated with abnormal DNA methylation. Hypermethylated epialleles of AGAMOUS (Jacobsen et al. 2000) and SUPERMAN (Jacobsen and Meyerowitz 1997; Jacobsen et al. 2000), which affect flower structure, and hypomethylated epialleles of FWA (Soppe et al. 2000), which delay flowering time, have been recovered from both mutagenized Arabidopsis populations and DNA hypomethylation lines such as $d d m 1, m e t 1$, and antisense-cytosine methyltransferase

\footnotetext{
${ }^{1}$ Corresponding author.

E-MAIL richards@biology.wustl.edu; FAX (314) 935-4432.

Article and publication are at http://www.genesdev.org/cgi/doi/10.1101/ gad.952102.
}

MET1 (Finnegan et al. 1996; Ronemus et al. 1996). Plant epimutations associated with altered DNA methylation can also occur spontaneously. Heritable, differentially methylated $P 1$ alleles that condition altered kernel pigmentation were reported in maize (Das and Messing 1994). Bender and colleagues have shown that an endogenous inverted repeat can induce methylation and silencing of homologous gene sequences (pai2) at an unlinked site in the Arabidopsis genome (Bender and Fink 1995; Jeddeloh et al. 1998; Luff et al. 1999; Melquist et al. 1999|. Recently, a naturally occurring floral variant of the plant Linaria was discovered to be caused by a hypermethylated, silenced Lcyc allele (Cubas et al. 1999). Fungi (Colot et al. 1996; Irelan and Selker 1997; Selker 1997) and animals (Michaud et al. 1994; Morgan et al. 1999) also show heritable epigenetic variation associated with differential DNA methylation.

We have been studying the effects of genomic hypomethylation using mutations in the DDM1 (DEEREASE IN $\underline{D} N A \underline{M E T H Y L A T I O N} \underline{1}$ ) gene of Arabidopsis. ddm1 mutations lead to a reduction in cytosine methylation throughout the genome (Vongs et al. 1993). Repeated DNA loses methylation immediately in $d d m 1$ mutants, but low copy sequences gradually lose methylation as $d d m 1$ mutants are propagated through successive generations by self-pollination (Kakutani et al. 1996). The DDM1 locus encodes a SWI2/SNF2-like protein that resembles chromatin remodeling engines in yeast, Drosophila, and humans (Jeddeloh et al. 1999).

$d d m 1$ loss-of-function mutations lead to developmental abnormalities including late flowering, dwarfing, and altered floral structures (Kakutani et al. 1996; Jacobsen et al. 2000). Typically, these defects are only observed after self-pollinating $d d m 1$ mutants for several generations. Arabidopsis normally is a self-pollinator, but $d d m 1 \mathrm{mu}-$ 
tants display the inbreeding depression typical of many outcrossing species. The $d d m 1$-induced developmental defects are caused by stable alterations at sites unlinked to the $d d m 1$ mutation (Kakutani et al. 1996). These alterations behave like classical Mendelian mutations and are stable when segregated from $d d m 1$. Some of these heritable alterations are caused by insertion of transposons, which are activated in $d d m 1$ mutants (Miura et al. 2001; Singer et al. 2001). However, $d d m 1$ also causes inherited epigenetic changes, including hypermethylated superman (sup) and agamous (ag) epialleles and hypomethylated fwa epialleles (Jacobsen et al. 2000; Soppe et al. 2000).

Here, we report the molecular mechanism underlying a $d d m 1$-induced pleiotropic defect bal that connects epigenetic regulation and plant pathogen defense responses. Several important molecular components involved in plant pathogen signaling have been identified, including plant resistance $(R)$ genes, salicylic acid $(\mathrm{SA})$, and pathogenesis-related $(P R)$ proteins (Hammond-Kosack and Jones 1996; Glazebrook 1999). $R$ genes encode proteins that recognize, either directly or indirectly, specific signals or gene products produced by pathogens, leading to the activation of defense signal transduction pathways (Ellis et al. 2000). The most common class of $R$-gene products consists of both a nucleotide-binding site (NBS) and multiple leucine-rich repeat (LRR) motifs (Hammond-Kosack and Jones 1997). There are 165 NBS-LRR (nucleotide binding site-leucine-rich repeat) class $R$-like genes in the Arabidopsis genome (for details, see http:// www.niblrrs.ucdavis.edu). One of the major induced pathways is dependent on salicylic acid (SA), a small aromatic compound related to aspirin (Durner et al. 1997). SA-dependent signaling induces $P R$ gene expression, which is correlated with elevated resistance (Uknes et al. 1992; Maleck et al. 2000). Several modifiers of SA signaling have been identified by mutations causing either constitutive expression of $P R$ genes (e.g., cpr [Bowling et al. 1994], ssi [Shah et al. 1999]) or nonexpression of PR genes (npr1; Cao et al. 1994, 1997; Ryals et al. 1997).

Our results indicate that bal is an epigenetic alteration mapping to a cluster of NBS-LRR-class disease-resistance genes. In the bal variant, overexpression of one gene in the cluster stimulates the disease response pathway and causes dwarfing and elevated disease resistance. Overexpression of a related NBS-LRR gene occurs in ssi1 (suppressor of $S A$ insensitivity 1) plants, which constitutively express $P \bar{R}$ genes (Shah et al. 1999). The overexpression phenotype and other genetic parallels suggest that the ssi1 mutant is mechanistically related to the bal variant.

\section{Results}

\section{bal is a heritable ddm1-induced defect}

Inbred Arabidopsis lines deficient in DNA methylation accumulate a spectrum of phenotypes, including late flowering, floral structure defects, and dwarfing (Kakutani et al. 1996; Jacobsen et al. 2000). To understand the molecular basis of such developmental abnormalities, we focused on a dwarfing variant (bal) generated in an inbred $d d m 1$ hypomethylation mutant line (strain Columbia). The bal phenotype is characterized by twisted leaves, dwarfed stature, and reduced fecundity (Fig. 1; Kakutani et al. 1996). We crossed a phenotypic bal ddm1 plant to wild-type Columbia and Landsberg erecta plants and generated segregating $\mathrm{F}_{2}$ populations. In these $\mathrm{F}_{2}$ families, the bal phenotype segregated as a single Mendelian trait independent of the $d d m 1$ mutation (Kakutani et al. 1996). The Columbia bal defect behaved as a semidominant allele relative to the wild-type Columbia $B A L$ allele (Fig. 1A), but acted in a recessive manner relative to the wild-type Landsberg erecta $B A L$ allele (Kakutani et al. 1996).

We followed the stability of the bal defect in four independent bal DDM1 lines propagated through five generations of self-pollination, and we observed no phenotypic reversion when the plants were grown under normal conditions. We conducted all subsequent phenotypic and molecular characterization of the bal defect using DDM1 wild-type backgrounds from Columbia and Landsberg erecta.

The bal variant resembles constitutive pathogen defense mutants

The morphology of the bal variant resembles Arabidopsis mutants that constitutively express pathogen defense

A
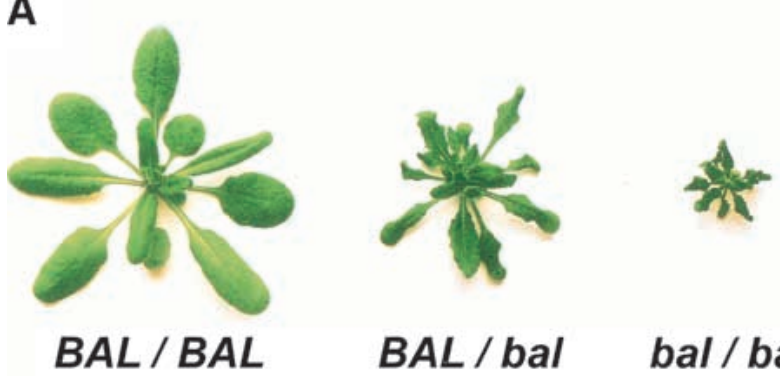

B

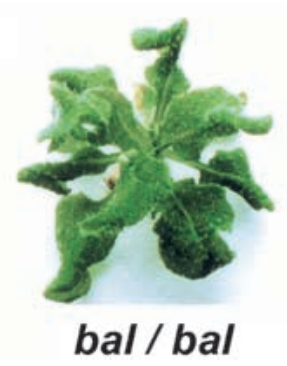

$B A L / b a l$

bal / bal

Figure 1. Phenotype of the semidominant bal defect. $(A)$ Twenty-five-day-old individuals (Columbia strain, wild-type DDM1) from a population segregating the bal alteration. Homozygous $\mathrm{bal} / \mathrm{bal}$ individuals show severe dwarfing and twisted leaves. Heterozygous individuals are intermediate in size and leaf twisting. (B) A higher-magnification view of bal/bal homozygotes compared with cpr1-1/cpr1-1 homozygotes (Columbia strain, 4 wk old). 
genes (e.g., cpr 1 [Bowling et al. 1994], mpk4 [Petersen et al. 2000], and ssi1 [Shah et al. 1999]). Figure 1B compares the morphology of bal homozygotes and plants homozygous for the cpr1 mutation. cpr1 was isolated from a chemical mutagenesis screen for plants that constitutively express $P R$ genes (Bowling et al. 1994). The morphological similarities prompted us to determine whether the bal variant also constitutively expresses $P R$ genes in the absence of pathogen. Figure $2 \mathrm{~A}$ shows that PR2 transcripts are expressed in uninfected bal and cpr1 homozygotes, but are absent in wild-type siblings. PR1 and PR5 transcripts were also expressed in uninfected bal (Fig. 2B) and cpr1 plants (data not shown.) PR2 transcript is detectable in $B A L / b a l$ heterozygotes, but at significantly lower levels compared with bal homozygotes (Fig. 2B). Therefore, the bal variant is a constitutive expresser of $P R$ genes.

Decreased pathogen growth and dwarf morphology in the bal variant are dependent on salicylic acid signaling

Because the bal variant constitutively expresses $P R$ genes, we sought to determine if the bal alteration af-
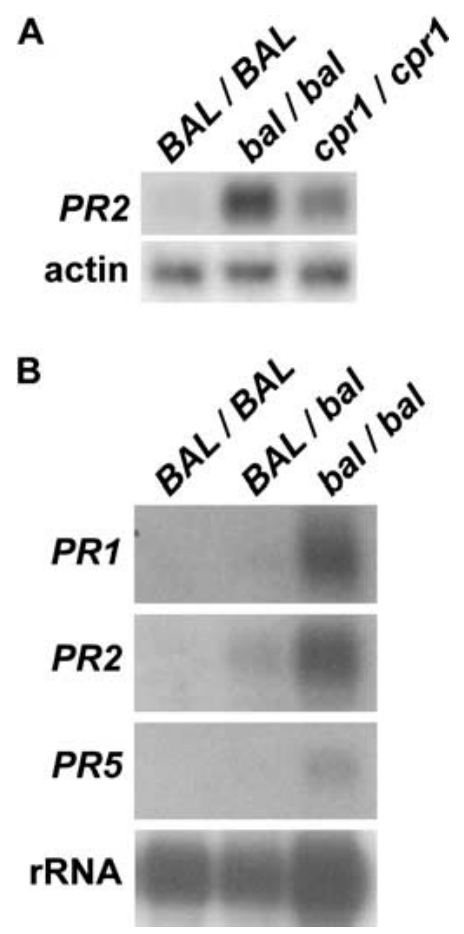

Figure 2. Constitutive expression of pathogenesis-related $(P R)$ protein genes in the bal variant. (A) Northern blot analysis using RNA samples prepared from uninfected wild-type $(B A L /$ $B A L), b a l / b a l$, and cpr1-1/cpr1-1 plants (all in strain Columbia). The membrane was first hybridized with a PR2 cDNA probe to show that the bal variant constitutively expresses $P R 2$, as does the positive control cpr1-1 mutant. The membrane was subsequently hybridized with an actin probe as a control for RNA loading. (B) Northern blot analysis examining expression of three $P R$ genes in wild-type $B A L / B A L$ plants, heterozygous $B A L / b a l$ and homozygous bal/bal siblings. fects resistance to pathogens. We investigated the growth of the bacterial pathogen, Pseudomonas syringae (pv. tomato strain DC 3000), to which Arabidopsis strain Columbia is susceptible (Whalen et al. 1991). Figure 3A shows that this virulent $P$. syringae strain grows $\sim 3$ orders of magnitude on wild-type Columbia hosts by $4 \mathrm{~d}$ postinoculation. Bacterial growth on bal homozygotes is attenuated; bacterial populations in bal homozygous leaf tissue are reduced 10- to 100-fold (Fig. 3A; data not shown) relative to populations in wild-type leaves at $4 \mathrm{~d}$ postinoculation.

Many plant defense responses are mediated through salicylic acid (SA)-dependent signaling pathways. Therefore, we examined whether the morphological and pathogenesis defects shown by bal homozygotes could be suppressed by disrupting SA signaling. We crossed the bal variant (strain Columbia) to an nahG transgenic line (strain Landsberg erecta; Delaney et al. 1994) expressing a microbial enzyme that inactivates SA. $P$. syringae (DC 3000) grows to a higher density on nahG transgenic tissue relative to wild-type Columbia tissues (Fig. 3A) and Landsberg erecta (data not shown). Bacterial growth in nahG bal homozygous tissue is also significantly higher than growth in either bal or wild-type plants. As shown in Figure 3B, nahG also significantly suppresses bal morphological defects, although the nahG bal plants retain some characteristics of the bal variant, such as mildly twisted leaves and reduced stature. These findings indicate that the full phenotypic expression of the bal variant is dependent on SA signaling.

\section{The bal defect is metastable}

Attempts to induce suppressor/revertant mutations in a bal DDM1 background resulted in the recovery of an unexpectedly high frequency of phenotypically normal plants or individuals with dramatically reduced bal phenotypes. We treated bal DDM1 seeds (M1) with either the alkylating agent ethylmethylenesulfonate (EMS) or $\gamma$-irradiation (see Materials and Methods). We recovered $>10 \%$ normal or phenotypically intermediate plants among the progeny (M2) of the plants grown from the EMS-treated seeds (Fig. 4, Table 1). In the $\gamma$-ray treated experiment, $\sim 7 \%$ of the M2 plants showed a wild-type or weakened bal phenotype. The mock-treated M2 populations contained no phenotypic revertants. The observed phenotypic reversion of bal in both experiments is at least 20 -fold greater than the expected recessive knockout frequency in a comparable Arabidopsis mutagenesis ( $0.1 \%$ of the M2 population; Haughn and Somerville 1987). Five phenotypically normal M2 plants were outcrossed to wild-type Columbia plants, and no segregation of phenotypically bal plants was seen in $F_{2}$ generations (among a total of $2040 \mathrm{~F}_{2}$ individuals examined). These results suggest that the restoration of the normal phenotype is caused by reversion of the bal allele rather than by the action of unlinked extragenic suppressors. 
Figure 3. Pathogenesis and morphology phenotypes of the bal variant are salicylic acid (SA)-dependent. (A) Growth of Pseudomonas syringae pv. tomato strain DC3000 is reduced in bal homozygotes relative to wild-type $B A L$ plants. $P$. syringae cultures $\left(1 \times 10^{5}\right.$ $\mathrm{CFU} / \mathrm{mL}$ ) were vacuum-infiltrated into whole plants at day 0 . The concentration of bacteria in leaf samples was determined at 0,2 , and $4 \mathrm{~d}$ postinoculation. Each measurement, in colony-forming units per centimeter squared $\left(\mathrm{CFU} / \mathrm{cm}^{2}\right)$ of leaf tissue, was done in triplicate; error bars on each data point indicate standard errors. Introduction of the $n a h G$ transgene suppresses the increased resistance phenotype of the bal defect (nahG, Landsberg erecta plants carrying a nahG transgene; bal nah $G$, homozygous individuals in a mixed Columbia and Landsberg erecta background). (B) The nah $G$ transgene partially suppresses the bal morphological phenotypes. Representative plants are shown (BAL, wild-type Landsberg erecta; bal nahG, homozygous individual in a mixed Columbia Landsberg erecta background; bal, Columbia bal homozygote).

\section{Characterization of the BAL locus}

The high frequency of bal reversion is consistent with either hypermutable genetic mechanisms (e.g., transposition, DNA rearrangements) or metastable epigenetic alterations (e.g., chromatin-controlled gene expression states). To determine the basis of the bal variant, we first sought to molecularly identify the $B A L$ locus. We mapped the bal alteration to a small genetic interval $(<0.2 \mathrm{cM})$ on the lower arm of Chromosome 4 (see Fig. 5A). This genetic interval corresponds to a $152-\mathrm{kb}$ window. The region has an $\sim 4$-fold increase in the ratio of physical to genetic distance, which in Arabidopsis normally averages $200 \mathrm{~kb} / \mathrm{cM}$ (Copenhaver et al. 1998). The observed recombination suppression is caused by strain-specific genomic rearrangements within the region (Parker et al. 1997; Noël et al. 1999).

A large portion of the physical window containing the bal alteration is composed of a $90-\mathrm{kb}$ gene cluster that contains 10 genes or gene fragments encoding NBS-LRRclass disease-resistance proteins (Parker et al. 1997; Bevan et al. 1998). Jones and colleagues discovered that the functional RPP5 (resistance to the downy mildew pathogen Peronospora parasitica) gene was embedded within this gene cluster in the Landsberg erecta strain (Parker et al. 1997). The Columbia version of the NBS-LRR gene cluster contains two apparently full-length, potentially
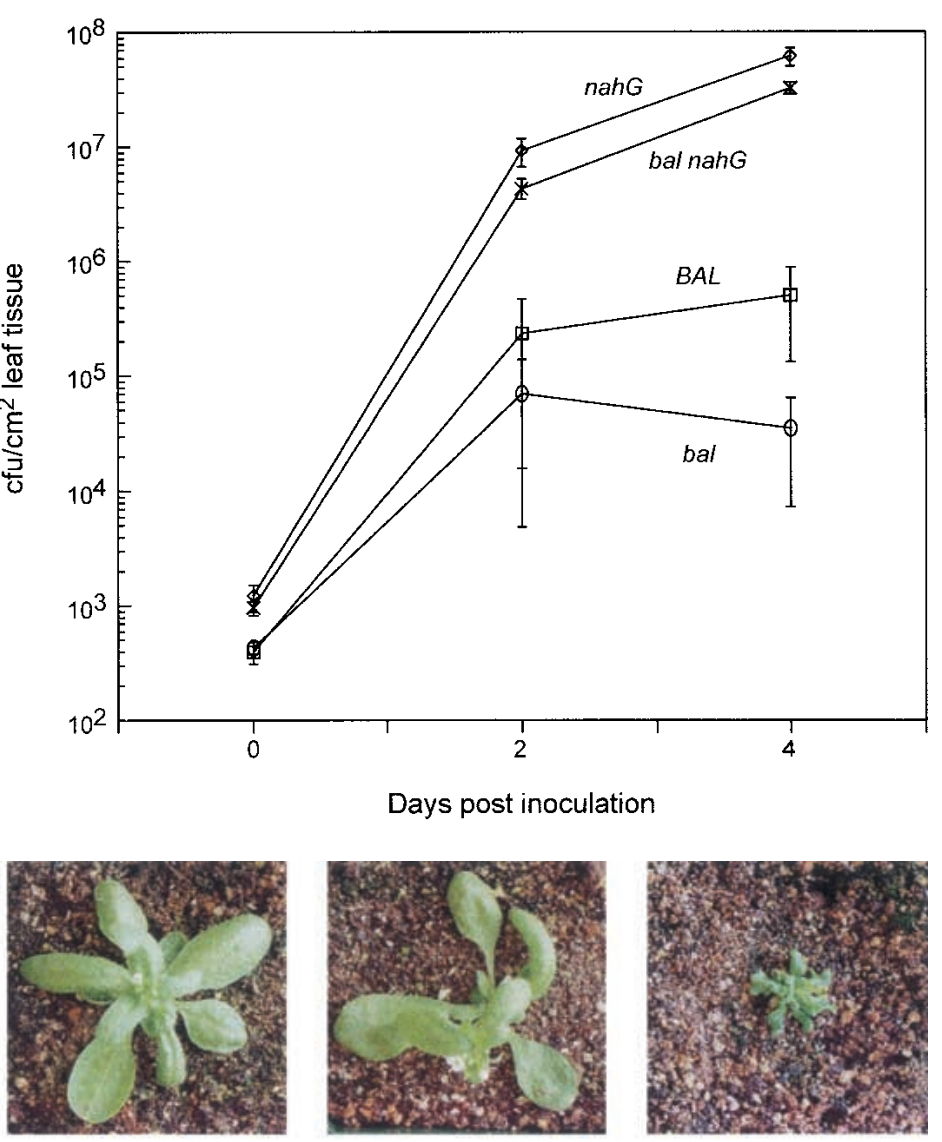

$B A L$

bal nahG

functional disease-resistance genes. The eight remaining NBS-LRR genes are fragments, or are interrupted by mutations or retrotransposon insertions. The $152-\mathrm{kb}$ window defined by our mapping contains 22 additional predicted genes (Bevan et al. 1998; http://mips.gsf.de).

\section{Gene expression profile in the bal variant}

We searched the 152-kb window for molecular changes correlated with the bal phenotype. We first screened for genomic alterations using Southern blots and hybridization probes tiling across the window. We found no DNA rearrangements in this comparison of bal and wild-type $B A L$ samples. In particular, we did not detect structural polymorphisms involving the two retrotransposable elements inserted into the NBS-LRR gene cluster (data not shown).

We next examined the transcripts originating from the NBS-LRR gene cluster using Northern blot analysis. We detected no transcripts from the two retrotransposons in the NBS-LRR cluster in either wild-type Columbia or bal homozygotes. However, hybridization probes corresponding to exons of the NBS-LRR genes detected a $5-\mathrm{kb}$ transcript in wild-type $B A L$ Columbia plants. This transcript species was overexpressed fourfold in bal compared with $B A L$ homozygotes (Fig. 6A). 

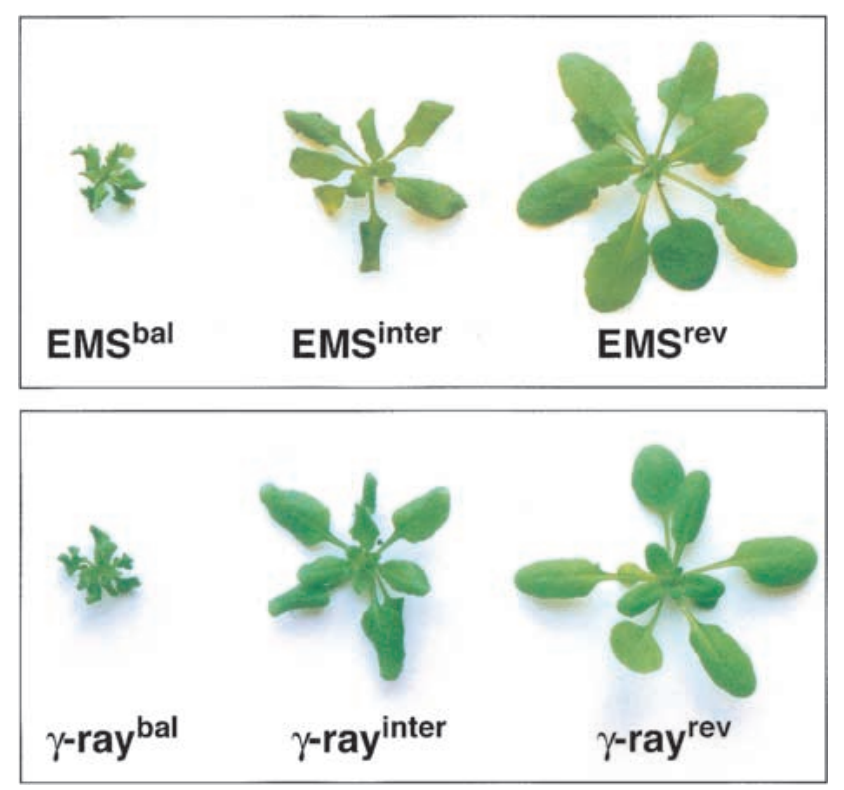

Figure 4. Representatives of the three phenotypic classes among M2 bal DDM1 populations treated with EMS or $\gamma$-rays. The two panels show M2 sibling plants characteristic of the three phenotypic classes in Table 1. (Top panel) EMS-treated M2 population; (bottom panel) $\gamma$-ray-treated M2 population. Superscripts indicate phenotypic severity: (bal) phenotypic; (inter) intermediate; (rev) revertant.

We investigated the correlation between the abundance of the $5-\mathrm{kb}$ transcript and the phenotypic severity of the bal defect by measuring transcript levels in EMSinduced revertants. As shown in Figure 6A, the abundance of the $5-\mathrm{kb}$ transcript was decreased to approximately wild-type levels in the EMS-induced revertants lacking bal variant phenotypes. Similar results were seen for the $\gamma$-ray-induced phenotypic revertants /data not shown). BAL/bal heterozygotes, which displayed intermediate phenotypes, contained an intermediate level of the $5-\mathrm{kb}$ transcript (Fig. 6B). The levels of the $5-\mathrm{kb}$ transcript were not elevated in nonphenotypic $d d m 1$ plants (data not shown).

\section{Expression of genes in the NBS-LRR gene cluster}

Because the NBS-LRR coding sequences in the region share $90 \%$ or greater nucleotide identity, Northern analysis was unable to distinguish among the different genes in the region. We took four approaches to identify which genes are expressed from the NBS-LRR cluster in wild-type Columbia (see Fig. 5B). First, a search of EST databases identified cDNA clones originating from four genes in the region (At4gxxxxx): 16890, 16900, 16950, and 16990. In addition, five EST matches were found for the two retrotransposons inserted into the penultimate 3 ' intron of At4g16860 and At4g16900. We also screened a wild-type Columbia cDNA library (Kieber et al. 1993) and isolated six additional clones that matched three genes: 16890, 16900, and 16950. As a supplementary ap- proach, we designed RT-PCR primers to amplify products corresponding to transcripts from the most intact NBS-LRR coding sequences in the cluster. Expression from individual NBS-LRR genes in the cluster was detected by RFLP or sequence analysis of the RT-PCR-amplified products. Sequence analysis of nine RT-PCR clones indicated that the major transcript in wild-type Columbia originates from the 16890 gene (5 of 9 clones); we also found expression from 16900 (3 of 9 clones) and 16950 (1 of 9 clones). RFLP analysis of bulk RT-PCR products supported the conclusion that the major transcript source in wild-type Columbia is the 16890 gene (data not shown). A parallel RT-PCR RFLP profile indicated that 16890 is also the major source of transcript in bal variant plants (data not shown). These analyses indicate that the 5-kb transcript detected on Northern blots (hereafter, referred to as the $B A L$ transcript) originates from the 16890 gene. The 16890 gene is one of the two genes in the cluster predicted to produce a fulllength NBS-LRR-class protein.

The DNA sequence of the At4g16890 gene is unchanged in the bal variant

To see if the observed overexpression of the 16890 gene was caused by a mutation, we determined the nucleotide sequence of a $7-\mathrm{kb}$ region from the bal variant encompassing the coding sequence of the gene and the entire upstream region up to the next annotated gene, 16900 (data not shown). No sequence changes were found. These data support the argument that the increased expression of the 16890 gene is not caused by a nucleotide sequence change.

\section{Overexpression of the At4g16890 gene phenocopies} the bal defect

We then asked if overexpression of the 16890 gene causes the bal phenotype. Using Agrobacterium-mediated T-DNA transformation, we constructed three independent transgenic lines (strain Columbia) containing

Table 1. Chemical and physical mutageneses cause bal reversion at a high frequency

\begin{tabular}{lcccc}
\hline & \multicolumn{3}{c}{ Phenotype } \\
\cline { 2 - 4 } Treatment & Wild-type & Intermediate & bal & \multirow{2}{*}{$n$} \\
\hline 0 mM EMS & \multirow{2}{*}{$2.5 \%$} & $8.8 \%$ & $100 \%$ & 1725 \\
30 mM EMS & & & $10.7 \%$ & 1102 \\
0 kRad $\gamma$-ray & \multirow{2}{*}{$5 \%$} & $5.6 \%$ & $92.8 \%$ & 525 \\
120 kRad $\gamma$-ray & $1.6 \%$ & 625 \\
\hline
\end{tabular}

bal/bal; DDM1/DDM1 seeds were treated with either ethylmethanesulfonate (EMS) or $\gamma$-rays, or mock-treated. The treated seeds (M1) were planted and M2 progeny were examined for the bal phenotype. $n$ indicates the number of M2 progeny examined. 
Stokes et al.

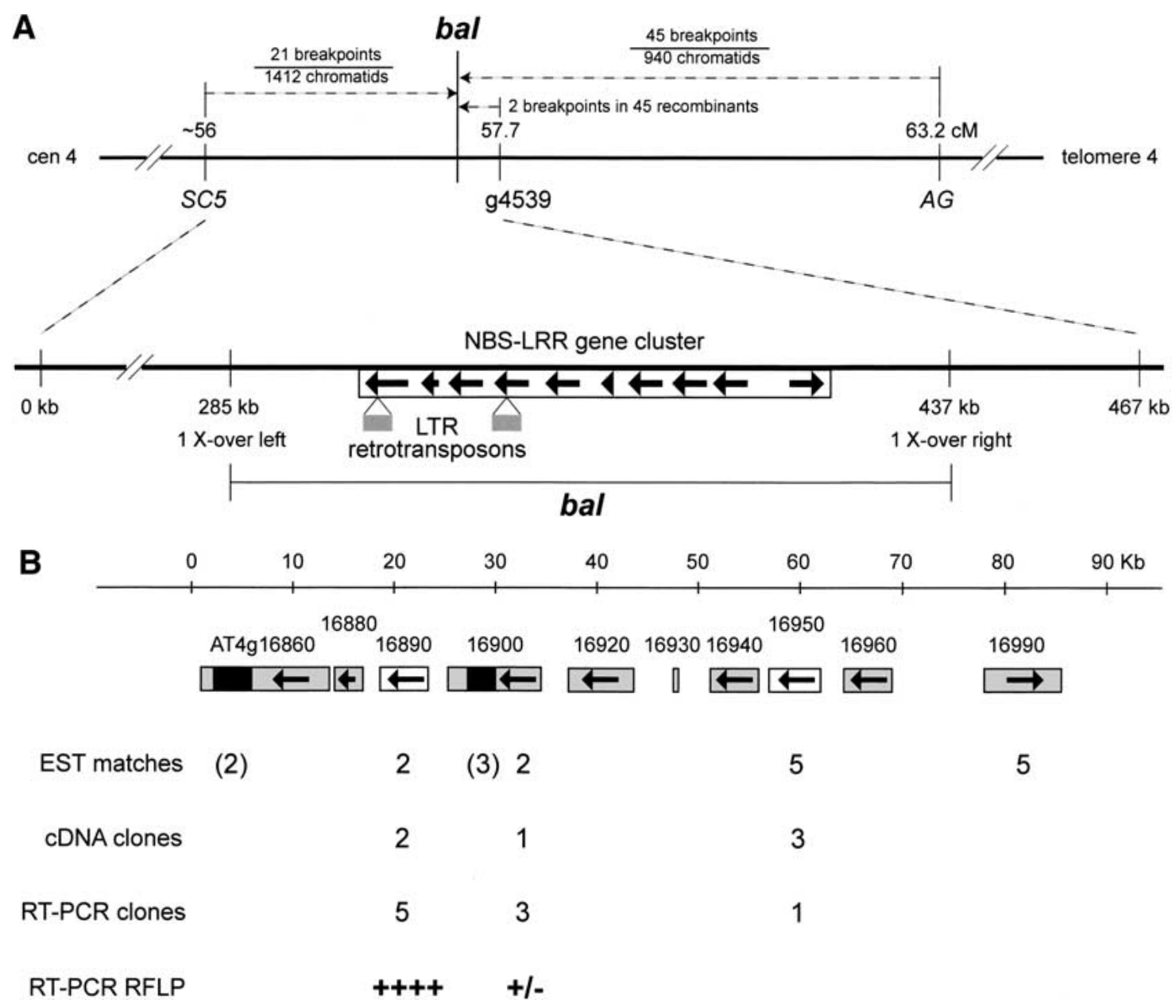

Figure 5. Map-based identification of the BAL locus. (A) (top) A genetic map of the region carrying the bal alteration. Distances are marked in centiMorgans $(\mathrm{cM})$, and relevant genetic markers are shown beneath the genetic map. The dashed lines above the genetic map indicate the distribution of recombination breakpoints in the region. (Bottom) A physical map of the region with the minimal genetic window containing the bal alteration shown by the bracketed line. The 90-kb NBS-LRR gene cluster (RPP5-like) from strain Columbia is shown, as well as the positions of two LTR retrotransposons. $(B)$ A higher resolution representation of the predicted RPP5-like genes (white and gray boxes) and LTR retrotransposons (filled boxes) in the 90-kb NBS-LRR gene cluster. Arrows indicate the predicted direction of transcription. Gray boxes indicate RPP5-like genes that are predicted to be nonfunctional because of point mutations and/or retrotransposon insertions. White boxes indicate genes predicted to encode functional NBS-LRR-class proteins. The results of our gene expression survey of the region are shown below the physical map. The number of matches in the public EST databases is indicated below each predicted coding sequence and the LTR retrotransposons (in parentheses). The number of matches to six newly isolated cDNA clones from the region is also shown. The distribution of sequenced RT-PCR clones and RFLP analysis of RT-PCR bulked products (data not shown) indicates that At4g16890 is the predominantly expressed gene in the cluster. Noël et al. (1999) use an alternative nomenclature to describe this region: At4g16890 = RPP5 homolog Col-B.

the 16890 gene driven by the strong viral promoter, P35S. In the first generation $\left(\mathrm{T}_{1}\right)$, we recovered 35S::BAL transgenic plants that phenocopied the dwarfing and twisted leaves of the bal variant. Control $\mathrm{T}_{1}$ transformants containing the vector construct without the 16890 gene always displayed a wild-type phenotype. These results indicate that the $35 S: \because B A L$ transgene recapitulates the bal phenotype (see Fig. 7). In $\mathrm{T}_{2}$ families generated by self-pollination of phenotypic $\mathrm{T}_{1} 35 S:: B A L$ transgenics, plants displaying the bal phenotype were recovered at a frequency of 55\% (96 bal::79 wild-type phenotype). The $T_{2}$ segregation ratios are consistent with stochastic silencing of the $35 S:: B A L$ transgene, which is frequently noted in 35S-driven transgenes in plants.

Next, we examined the expression of the 16890 gene using Northern analysis in the $\mathrm{T}_{2}$ generation comparing individuals with wild-type or bal phenotypes. As shown in Figure 8, the level of the 5-kb $B A L$ transcript was elevated in transgenic plants showing the bal phenotype. No increase in the abundance of the $B A L$ transcript was noted in nonphenotypic segregants. Moreover, $P R 1$ gene expression was elevated in $355:: B A L$ phenotypic individuals but was absent in nonphenotypic segregants. Based on progeny tests for the transgenic kanamycin-resistance marker, some of the nonphenotypic $\mathrm{T}_{2}$ individuals seg- 
A

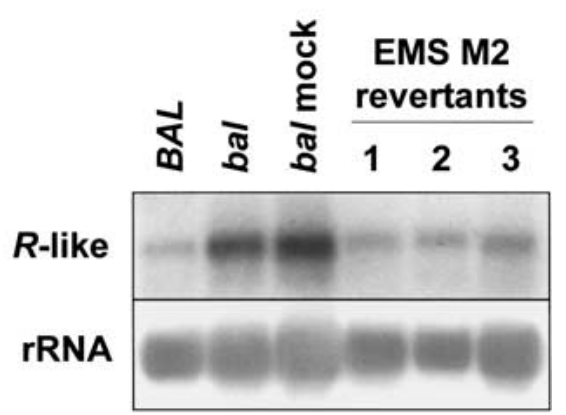

B

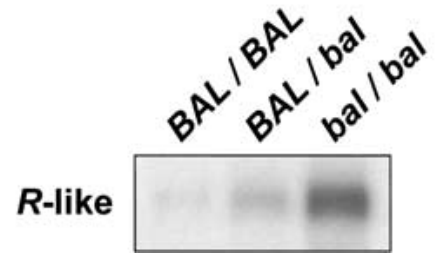

Figure 6. Overexpression of an NBS-LRR gene is associated with the bal phenotype. (A) Northern blot analysis showing overexpression of an NBS-LRR-like gene in phenotypic bal variants. (BAL) $B A L / B A L$; (bal) bal/bal variant; (bal mock) phenotypic plants from the mock-treated EMS M2 population; $(1,2,3)$ independent nonphenotypic revertant plants from an EMStreated M2 population. (Bottom panel) RNA loading control. (B) Northern blot analysis showing that the NBS-LRR like transcript level correlates with phenotypic severity in a population segregating the bal variant allele. The autoradiogram resulted from hybridization of the membrane used in Figure 2.

regated kanamycin-resistant seedlings in the $\mathrm{T}_{3}$ generation, consistent with the hypothesis that silencing of the 35S::BAL transgene occurs. However, all $\mathrm{T}_{2}$ bal phenotypic plants contained the $35 S: \because B A L$ transgene and overexpressed the 5-kb $B A L$ transcript.

The transgenic data support the hypothesis that overexpression of an NBS-LRR gene causes the bal phenotype. This result was corroborated by the phenotype of bal eds1-2 double mutants (data not shown). EDS1 distinguishes TIR (toll interleucin receptor) and LZ (leucine zipper) classes of NBS-LRR gene products; eds1 mutations block signaling downstream of TIR, but not LZ, class $R$-genes (Aarts et al. 1998; Clarke et al. 2001). The eds1-2 mutation suppressed the bal morphology and constitutive $P R$ gene expression phenotype (data not shown), consistent with the 16890 gene being a TIRclass $R$-gene.

Overexpression of R-gene coding sequence in suppressor of SA insensitivity 1 (ssi1) variant

There are several parallels between the phenotype and genetics of the bal variant and the ssi1 mutant. The ssi1 mutation was isolated in the Nossen background as an extragenic suppressor of an npr1 (nonexpresser of pathogenesis-related genes) mutation (S̄hah et al. 1999). Like the bal variant, the phenotype of the ssil mutant is characterized by dwarfing, narrow leaves, and reduced fertil- ity. The phenotypic effects of the ssi1 mutation and the bal variant are not dependent on the npr1 mutation (data not shown). The ssi1 mutant shows constitutive $P R$ gene expression and decreased growth of $P$. syringae. The ssi1 dwarfing and constitutive $P R$ gene expression are suppressed by the presence of the nahG transgene, indicating that these phenotypes are SA-dependent. The ssi1 mutation is semidominant to the Nossen SSI1 allele and maps to the lower arm of Chromosome 4 close to the $B A L$ locus (Shah et al. 1999).

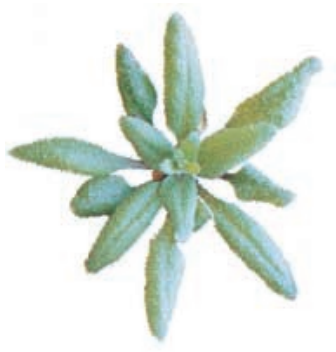

$B A L / B A L$

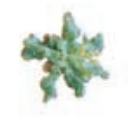

bal / bal

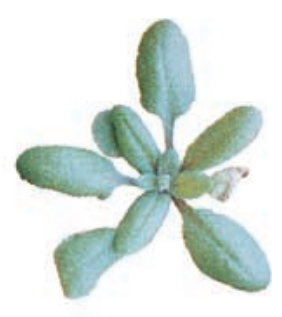

$B A L / B A L$ (vector only)
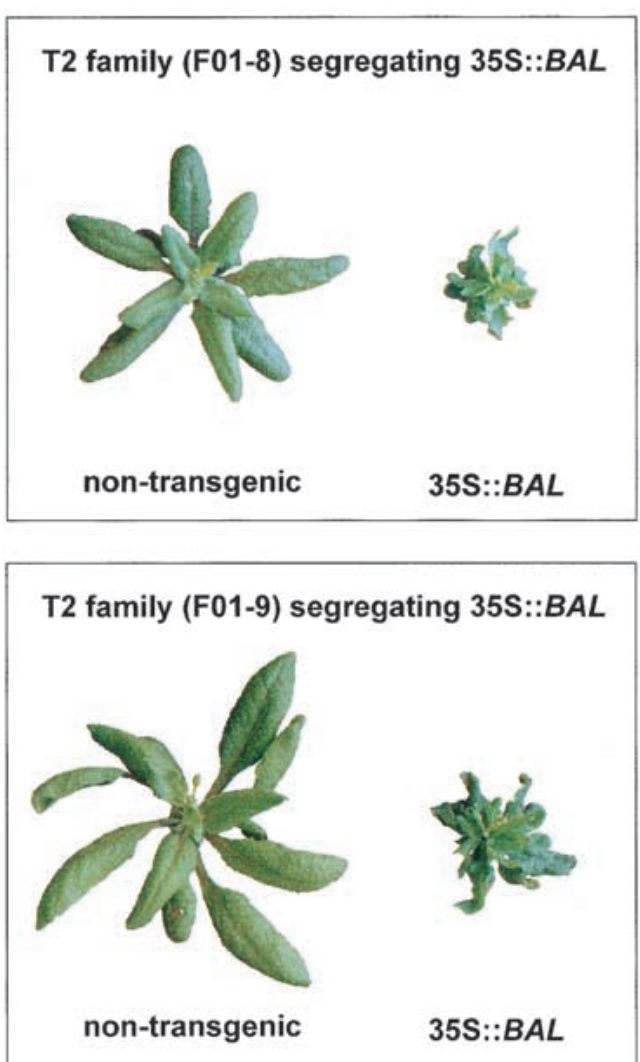

Figure 7. Overexpression of At4g16890 in transgenic plants phenocopies the bal variant. (Top) Control plants: $(B A L / B A L)$ wild type; (bal/bal) homozygous bal variant, $(B A L / B A L$ vector only) wild type transformed with the T-DNA vector (pMD1). (Middle, bottom) Segregation of the dwarfing bal phenotype is shown by representative plants from two $\mathrm{T}_{2}$ families segregating the $35 S:: B A L$ transgene. All plants pictured (Columbia strain background) are 24-day-old plants and were grown in parallel in an environmental chamber. 
Figure 8. Transcript analysis of $35 S:: B A L$ transgenics. (Top panel) Northern blot of total RNA hybridized with an $R$-like probe recognizing the $\sim 5-\mathrm{kb} B A L$ transcript. (Middle panel) The membrane was rehybridized with a probe recognizing the $P R 1$ transcripts. (Bottom panel) The membrane was rehybridized again with a $25 \mathrm{~S}$ rRNA gene probe as an RNA loading control. Two control lanes are shown on the left: $(B A L)$ wild type; (bal) bal/bal DDM1/DDM1 variant. The remaining lanes contain total RNA prepared from six individuals (wild-type phenotype vs. bal phenotype) from two independent $\mathrm{T}_{2}$ families segregating a $35 \mathrm{~S}:: B A L$ transgene. All plants are in the Columbia background.

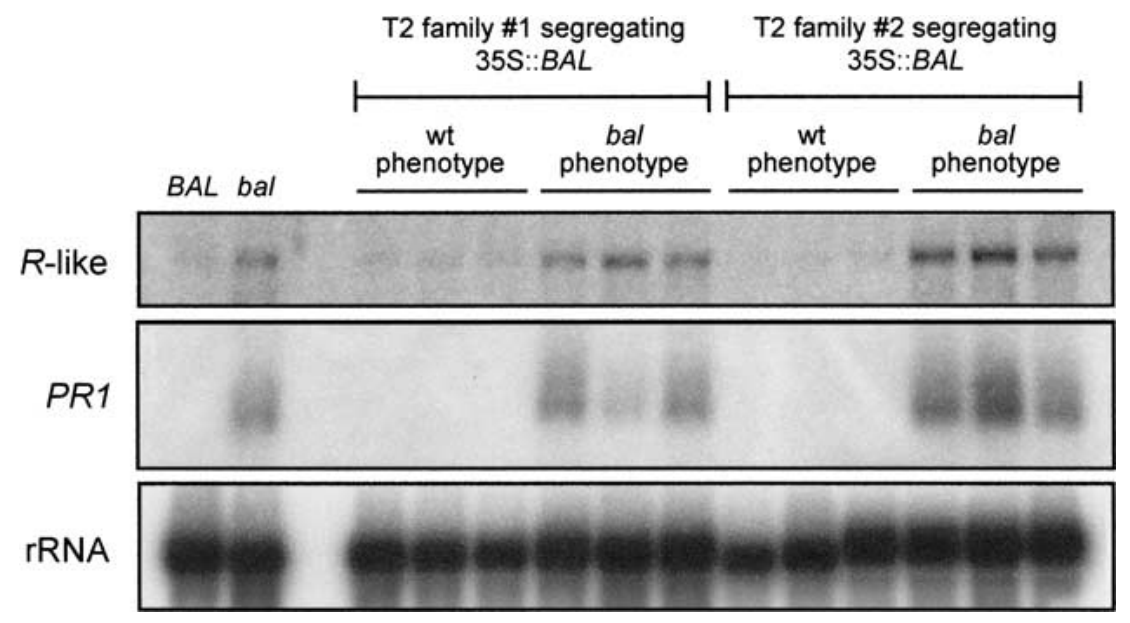

The genetic and phenotypic parallels between the bal and ssi1 defects led us to investigate the ssi1 variant further. First, we examined the stability of the ssi1 phenotype in response to EMS mutagenesis. We found a high frequency of phenotypically normal or intermediate plants in the M1 generation: 14\% (50 mM EMS) and 9\% (120 krad of $\gamma$-irradiation) compared with $0 \%$ in mocktreated controls. Next, we investigated the expression within the Chromosome 4 NBS-LRR gene cluster in the ssi1 variant and the appropriate wild-type background. Figure 9 shows that in the Nossen background, the level of the transcript was increased in the ssil variant. The metastability of the ssi1 variant and its association with the overexpression of an $R$-like gene further suggest that the ssil and bal variants may be caused by the same underlying mechanism.

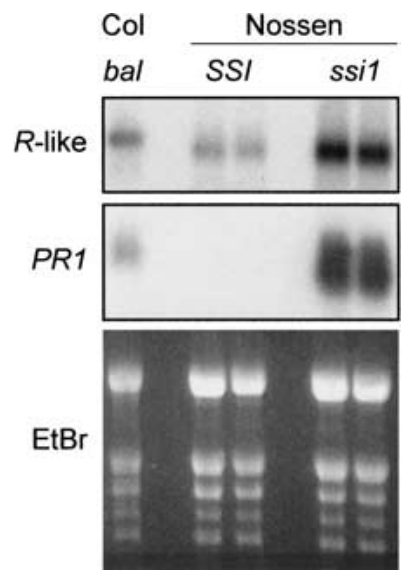

Figure 9. Overexpression of an RPP5-like gene in the ssi1 (suppressor of $S A$ insensitivity 1) mutant. Northern blot analysis using an $R \bar{P} P 5$-like hybridization probe detected the $B A L$ transcript in the Columbia bal variant (bal) and recognized a smaller message in Nossen compared with Columbia. The abundance of the cross-hybridizing transcript is elevated in the ssi1 mutant relative to a wild-type Nossen contrl. (Bottom panel) RNA loading control.

\section{Discussion}

Here, we show that a $d d m 1$ mutation induced a stable alteration, bal, which activates plant defense responses in the absence of pathogens. Several lines of evidence suggest that bal is an epigenetic variant. First, the bal alteration arose in an inbred $d d m 1$ hypomethylation background known to produce epigenetic variation (e.g., sup [Jacobsen et al. 2000], ag [Jacobsen et al. 2000], and fwa [Soppe et al. 2000] epialleles). Second, the bal alteration causes a change in gene expression that is not associated with large-scale genomic alterations or changes in nucleotide sequence of the implicated At4g16890 gene. Third, the bal alteration can be destabilized in response to DNA-damaging agents, consistent with previous demonstrations that mutagens can alter DNA methylation and produce epigenetic alleles that are either hypomethylated or hypermethylated (Riggs and Jones 1983; Wilson and Jones 1983; Jacobsen and Meyerowitz 1997; Soppe et al. 2000). Furthermore, our preliminary results indicate that the Chromosome $4 R$-like gene cluster and associated LTR retrotransposons are methylated in wildtype Columbia, and that this region is hypomethylated in $d d m 1$-inbred backgrounds (T.L. Stokes and E.J. Richards, unpubl.). We hypothesize that overexpression of At4g16890 in the bal variant is caused by heritable hypomethylation of critical sites in the region or is triggered by hypomethylation below a threshold level. Although we have found hypomethylated sites in the $R$ gene cluster of the bal variant, we have not yet identified methylation changes that are strictly correlated with At4g16890 overexpression.

In our study, overexpression of the At4g16890 R-like gene in both the bal variant and transgenic Arabidopsis induces defense responses in the absence of pathogen. Previous studies show that overexpression of a non-LRRclass resistance gene Pto or an LRR-NBS resistance gene Prf induces defense responses and enhances pathogen resistance in transgenic tomato (Oldroyd and Staskawicz 1998; Tang et al. 1999|. In contrast to the bal variant and the 35S::BAL Arabidopsis transgenics, tomato plants overexpressing Pto or Prf fail to show dramatic whole- 
plant defects. Recently, Xiao et al. (2001) reported that the overexpression of $R P W 8$, a novel $R$-gene locus containing two genes, in Arabidopsis leads to broad-spectrum fungal resistance without obvious phenotypic abnormalities. The different phenotypic consequences of $R$-gene overexpression may reflect peculiarities of the different plant species and/or specific interactions of the different resistance genes. We note that some signaling mutants that affect steps downstream of $R$-genes show dwarfing and twisted leaf phenotypes (e.g., cpr1 [Bowling et al. 1994], mpk4 [Petersen et al. 2000]), which closely resemble the bal variant phenotype.

$R$-gene products act to recognize, either directly or indirectly, specific pathogen strains. After recognition, $R$ gene products signal through one or more defense pathways (Glazebrook 1999). The BAL gene is transcribed in the absence of pathogen, and the level of the transcript is not increased by pathogen attack (data not shown). Most characterized NBS-LRR $R$-genes are expressed at low constitutive levels (e.g., Meyers et al. 1999) similar to that seen for the $B A L$ transcript. Mild developmental phenotypes were seen in $B A L / b a l$ heterozygotes that express $\sim 2.5$-fold higher levels of the $B A L$ transcript. Severe morphological abnormalities resulted from a fourfold overexpression of the $B A L$ transcript, levels similar to the highest seen in recovered $35 S:: B A L$ transgenics. These results suggest that the expression of the $B A L$ transcript may be constrained to an upper limit of expression.

Our results also address the mechanism of the ssi1 variant, which was originally identified in the Nossen background as a suppressor of npr1-5 (Shah et al. 1999). Several pieces of evidence indicate that bal and ssi1 variants are caused by the same mechanism. First, both bal and ssi1 are semidominant alterations that cause dwarfing and activation of defense pathways independent of NPR1 function. Second, the ssi1 mutation maps to the same genetic region $(<5 \mathrm{cM})$ as the $B A L$ locus. Third, both bal and ssil overexpress an $R$-like gene from the cluster mapping to the bottom arm of Chromosome 4 . Finally, both the bal and ssi1 variants are destabilized by mutagens. Our results suggest that the ssi1 phenotype is caused by overexpression of an LRR-NBS $R$-like gene, which may be tied to a metastable epigenetic alteration.

The semidominant nature of the bal and ssil alterations is consistent with the proposed overexpression mechanism. BAL/bal heterozygotes expressed $\sim 2.5$ times the level of $B A L$ transcript compared to wild-type $B A L / B A L$ homozygotes in a Columbia background. Interestingly, the Columbia bal alteration behaved as a recessive allele when crossed into a wild-type Landsberg erecta background. The RPP5 NBS-LRR haplotype in Landsberg erecta is rearranged relative to Columbia, and we have not detected a corresponding $B A L$ transcript from the Landsberg locus (data not shown). Combination of a 4 -overexpressing Columbia bal allele with a null Landsberg allele is not sufficient to exceed a threshold for phenotypic expression. On the other hand, combination of a $4 \times$-overexpressing Columbia bal allele with a 1×-expressing Columbia $B A L$ allele exceeds this thresh- old, leading to mild phenotypic consequences. We note that the Columbia bal allele in combination with a wildtype Nossen allele acted semidominantly, consistent with the idea that the wild-type Nossen allele can specify some $R$-like gene function (data not shown). The overexpression model of ssi1 is also consistent with recent findings that SSI1/SSI1/ssi1 triploid progeny (tetraploid Columbia $\times$ Nossen ssi1 diploid) fail to show morphological phenotypes (Greenberg 2000). In this case, the presence of the two wild-type Columbia loci in a triploid background would dilute the $R$-like gene function below the critical threshold.

Resistance genes are highly reiterated in plants, and our results point toward the importance of epigenetic regulation of these gene clusters prevalent in plant genomes. For example, the Arabidopsis genome, once believed to be relatively simple in structure, contains $\sim 37 \%$ of the predicted protein coding sequences in families of five members or more, and $17 \%$ of all predicted Arabidopsis genes are multicopy and tandemly arrayed (The Arabidopsis Genome Initiative 2000). Our results suggest that epigenetic modification may play an important role in regulating gene clusters by cementing silent or intermediate expression states.

Recent results from several groups suggest that epigenetic alterations may play an important role in controlling phenotypic variation in both laboratory and natural populations. In Arabidopsis laboratory strains, epigenetic variation at several loci has been induced by both chemical mutagenesis and DNA hypomethylation (Jacobsen and Meyerowitz 1997; Jacobsen et al. 2000; Soppe et al. 2000). The induced epialleles described to date fall into two categories: metastable, silenced hypermethylated alleles (ag, sup, and pai2) and stable, hypomethylated epialleles associated with ectopic gene expression (fwa). The stability of the bal alteration is consistent with the hypothesis that DNA hypomethylation is involved. The recent discovery of hypermethylated silenced Lcyc alleles in Linaria shows that epigenetic variation can affect plant morphology and fitness in natural populations as well (Cubas et al. 1999). The induced genomic alterations characterized here (bal and ssi1) can modulate pathogen-plant interactions, raising the possibility that similar variants might arise and be selected in natural populations.

\section{Materials and methods}

\section{Plant growth}

Plants were grown in a mixture of Redi-Earth (Scotts):vermiculite $(60 \%: 40 \%)$ in environmental growth chambers ( $16 \mathrm{~h}$ of illumination [fluorescent + incandescent]/day, $70 \%$ relative humidity, $22^{\circ} \mathrm{C}$ ) or under similar conditions in a greenhouse. Under short day length ( $8 \mathrm{~h}$ of illumination/day) and high humidity $(95 \%)$, the morphological phenotypes of bal are attenuated. bal plants grown under short day length were used for the $P$. syringae inoculations (see Fig. 3).

\section{Genetic mapping of the bal defect}

The bal variant was generated from a $d d m 1-2$ line in the Columbia strain background, self-pollinated through six genera- 
tions. We mapped bal in an $\mathrm{F}_{2}$ segregating population generated from a cross between a bal/bal; DDM1/DDM1 (Columbia) plant and a $B A L / B A L ; D D M 1 / D D M 1$ (Landsberg erecta) individual (Kakutani et al. 1996). Phenotypic bal/bal $\mathrm{F}_{2}$ plants were genotyped initially using the flanking CAPS markers, AG and SC5 (Konieczny and Ausubel 1993; http://www.arabidopsis.org). We generated new CAPS markers from the available genomic sequence (Bevan et al. 1998) to establish a genetic and physical interval containing the bal alteration. This window is defined by a centromere-proximal marker: forward primer, 5 '-AGACG CTGGAGTATCTTCACC-3'; reverse primer, 5'-CAGGAGGT GAGTTTCATCCTC-3'; polymorphic TaqI site and a telomereproximal marker: forward primer, $5^{\prime}$-AATCATTGTCACCGAT CACC-3'; reverse primer, 5'-TGTACCGCCGTTCTGCTAC3'; polymorphic HaeIII site.

\section{Nucleic acid isolation and analysis}

Genomic DNA samples were purified using QIAGEN protocols and columns, or by the Urea Lysis miniprep protocol (Cocciolone and Cone 1993). Southern analyses were performed as described previously (Jeddeloh et al. 1998). Total RNA samples were isolated using either QIAGEN RNeasy or Bio-Rad AquaPure protocols. RNA was size-fractionated by electrophoresis through $1.5 \%$ agarose formaldehyde gels and blotted to GeneScreen (NEN DuPont) nylon membranes using capillary action and $50 \mathrm{mM}$ sodium phosphate buffer ( $\mathrm{pH}$ 6.5). All hybridizations were done following the protocol of Church and Gilbert (1984), and membranes were washed at $60^{\circ} \mathrm{C}$ in $0.2 \times \mathrm{SSC}, 0.1 \%$ SDS. Hybridization probes were radiolabeled using the random priming protocol (Feinberg and Vogelstein 1983), and unincorporated radionucleotides were removed by size-filtration columns. We used the following hybridization probes: Arabidopsis actin 2 gene (GenBank U41998); PR1 (Uknes et al. 1992); PR2 (Dong et al. 1991); PR5 (Uknes et al. 1992); R-like gene (ColF; Parker et al. 1997); 25S rRNA gene (pARR17; Kakutani et al. 1996). DNA sequencing was performed using linear doublestranded templates generated by genomic amplification and BigDye Terminator Cycle Sequencing (Perkin-Elmer) protocols/reagents.

\section{bal reversion analysis}

bal/bal; DDM1/DDM1 seeds were hydrated overnight in water and then treated with different concentrations of EMS $(0,10,20$, 30, 40, and $50 \mathrm{mM}$; Sigma M0880) for $8 \mathrm{~h}$. Seeds were then washed overnight in water, dried, and sown on soil. The resulting $\mathrm{M} 1$ plants were allowed to grow to maturity, and self-pollinated M2 seeds were harvested in independent batches $(\sim 20$ M1 plants per M2 pool). A similar protocol was followed for the $\gamma$-ray mutagenesis experiments except that dried seeds were treated by exposure to a $\gamma$-ray source (Department of Radiology, Washington University Medical School). The data shown in Table 1 represent the pooling of at least three M2 families.

\section{BAL transcript analysis}

A wild-type Columbia cDNA library (Kieber et al. 1993) was screened $\left(7.5 \times 10^{5}\right.$ plaques $)$ using a probe that represented a conserved portion of the open reading frames in the gene cluster. RT-PCR analysis used poly(A)+-selected (Dynabeads) RNA and the following primers: forward primer, 5'-AGAAATTGA TCGTGCAAAGTCCAAGGGTAATCC-3'; reverse primer, 5' AGAGTTCCTTCCCACAGTTTCTCAAGCTTACT-3'; with Stratascript II (Stratagene) RT enzyme. The amplified products, corresponding to exon 2-intron 2-exon 3 from AT4g16890, were either sequenced using Big-Dye Terminator Cycle Sequencing (Perkin Elmer) protocols/reagents or were digested with HaeIII and/or HphI (New England Biolabs), which distinguished among At4g16860, 16890, 16900, 16920, and 16950.

\section{Generation of transgenic plants}

The genomic region encompassing the At4g16890 gene was amplified using the following primers: forward primer, $5^{\prime}$-CTAG TCTAGACGGCAAATTGTTTCGTGGCCATCTTGTCA-3'; reverse primer, 5'-CGCGGATCCCAATGTGGAAAAGATAG ATGTATGGTAC-3'. The ends of the resulting 5-kb fragment were cut with $\mathrm{XbaI}$ and $\mathrm{BamHI}$ (New England Biolabs), and the fragment was cloned into the pMD1 vector (a derivative of pBI121; Mark Dixon, unpubl.) downstream of a strong viral promoter, P35S. The amplified 35S::16890 gene encodes a fulllength protein with one missense mutation at position 950 in the LRR domain (S $950 \mathrm{~L}$ ). Only 8 of the 21 LRRs in RPP5 (the closest relative in the Arabidopsis genome) contain a leucine adjacent (toward the $\mathrm{N}$ terminus) to the altered position, which is occupied by either serine or isoleucine. The poor conservation at this position and the similar structure of leucine and isoleucine suggest that the change will not alter the function of the gene product. The construct was electroporated into Agrobacterium tumefaciens strain GV 3101 (Koncz and Schell 1986). Plants were transformed using the floral dip protocol (Clough and Bent 1998). Harvested seeds were ethanol- and bleach-sterilized, and transformants were selected on plates with $4.6 \%$ Murashige and Skoog salts (GIBCO-BRL), Gamborg's vitamins (Sigma), and $50 \mathrm{mg} / \mathrm{L}$ kanamycin (Sigma).

\section{Characterization of pathogen defense response}

Five-week-old Arabidopsis plants were inoculated by vacuum infiltration with Pseudomonas syringae p.v. tomato strain DC3000 (Whalen et al. 1991) at an initial density of $1 \times 10^{5}$ $\mathrm{CFU} / \mathrm{mL}$. The concentration of bacteria in the plant leaves was assayed after 0,1 , and $4 \mathrm{~d}$ as described previously (Whalen et al. 1991). Data points represent the means of three independent determinations \pm standard error of the mean. nahG bal double mutants were identified by testing for kanamycin resistance (linked to the nahG transgene) and scoring a CAPS marker closely linked to bal: forward primer, 5'-AGACGCTGGAGT ATCTTCACC-3'; reverse primer, 5'-CAGGAGGTGAGTTTC ATCCTC-3'; polymorphic TaqI site. Northern blots were done on double mutants to verify that At4g16890 and nahG were expressed at expected levels (data not shown). Crosses were done between bal/bal and npr1-1/npr1-1 plants and double mutants in the $\mathrm{F}_{2}$ generation were identified by first scoring for dwarfing and then genotyping at the NPR1 locus using a molecular marker. A similar approach was used to generate bal eds1-2 double mutants.

\section{Acknowledgments}

This work was supported by grants from the National Science Foundation to E.J.R. (MCB9306266, MCB9604972, and MCB9985348) and from the National Institutes of Health to B.N.K. (GM52536). T.L.S. was supported in part by a predoctoral fellowship from the Monsanto Company. We thank X. Dong (cpr1), D. Klessig (ssi1), and J. Parker (eds1-2) for generously providing seeds. We gratefully acknowledge William D. Wright (Washington University, Department of Radiology) for assistance with the $\gamma$-irradiation, Katherine Mason for technical assistance, and Mike Dyer for greenhouse management. 
The publication costs of this article were defrayed in part by payment of page charges. This article must therefore be hereby marked "advertisement" in accordance with 18 USC section 1734 solely to indicate this fact.

\section{References}

Aarts, N., Metz, M., Holub, E., Staskawicz, B.J., Daniels, M.J., and Parker, J.E. 1998. Different requirements for EDS1 and $N D R 1$ by disease resistance genes define at least two $R$ genemediated signaling pathways in Arabidopsis. Proc. Natl. Acad. Sci. 95: 10306-10311.

The Arabidopsis Genome Initiative. 2000. Analysis of the genome sequence of the flowering plant Arabidopsis thaliana. Nature 408: 796-815.

Bender, J. and Fink, G.R. 1995. Epigenetic control of an endogenous gene family is revealed by a novel blue fluorescent mutant of Arabidopsis. Cell 83: 725-734.

Bevan, M., Bancroft, I., Bent, E., Love, K., Goodman, H., Dean, C., Bergkamp, R., Dirkse, W., Van Staveren, M., Stiekema, W., et al. 1998. Analysis of $1.9 \mathrm{Mb}$ of contiguous sequence from chromosome 4 of Arabidopsis thaliana. Nature 391: 485-488.

Bowling, S.A., Guo, A., Cao, H., Gordon, A.S., Klessig, D.F., and Dong, X. 1994. A mutation in Arabidopsis that leads to constitutive expression of systemic acquired resistance. Plant Cell 6: 1845-1857.

Cao, H., Bowling, S.A., Gordon, A.S., and Dong, X. 1994. Characterization of an Arabidopsis mutant that is nonresponsive to inducers of systemic acquired resistance. Plant Cell 6: 1583-1592.

Cao, H., Glazebrook, J., Clarke, J.D., Volko, S., and Dong, X. 1997. The Arabidopsis NPR1 gene that controls systemic acquired resistance encodes a novel protein containing ankyrin repeats. Cell 88: 57-63.

Church, G.M. and Gilbert, W. 1984. Genomic sequencing. Proc. Nat1. Acad. Sci. 81: 1991-1995.

Clarke, J.D., Aarts, N., Feys, B.J., Dong, X., and Parker, J.E. 2001. Constitutive disease resistance requires EDS1 in the Arabidopsis mutants cpr1 and cpr6 and is partially EDS1-dependent in cpr5. Plant J. 26: 409-420.

Clough, S.J. and Bent, A.F. 1998. Floral dip: A simplified method for Agrobacterium-mediated transformation of Arabidopsis thaliana. Plant J. 16: 735-743.

Cocciolone, S.M. and Cone, K.C. 1993. Pl-Bh, an anthocyanin regulatory gene of maize that leads to variegated pigmentation. Genetics 135: 575-588.

Colot, V., Maloisel, L., and Rossignol, J.L. 1996. Interchromosomal transfer of epigenetic states in Ascobolus: Transfer of DNA methylation is mechanistically related to homologous recombination. Cell 86: $855-864$.

Copenhaver, G.P., Browne, W.E., and Preuss, D. 1998. Assaying genome-wide recombination and centromere functions with Arabidopsis tetrads. Proc. Natl. Acad. Sci. 95: 247-252.

Cubas, P., Vincent, C., and Coen, E. 1999. An epigenetic mutation responsible for natural variation in floral symmetry. Nature 401: 157-161.

Das, O.P. and Messing, J. 1994. Variegated phenotype and developmental methylation changes of a maize allele originating from epimutation. Genetics 136: 1121-1141.

Delaney, T.P., Uknes, S., Vernooji, B., Friedrich, L., Weymann, K., Negrotto, D., Gaffney, T., Gut-Rella, M., Kessmann, H., Ward, E., et al. 1994. A central role of salicylic acid in plant disease resistance. Science 266: 1247-1250.

Dong, X., Mindrinos, M., Davis, K.R., and Ausubel, F.M. 1991.
Induction of Arabidopsis defense genes by virulent and avirulent Pseudomonas syringae strains and by a cloned avirulence gene. Plant Cell 3: 61-72.

Durner, J., Shah, J., and Klessig, D.F. 1997. Salicylic acid and disease resistance in plants. Trends Plant Sci. 2: 266-274.

Ellis, J., Dodds, P., and Pryor, T. 2000. Structure, function and evolution of plant disease resistance genes. Curr. Opin. Plant Biol. 3: 278-284.

Fedoroff, N., Schlappi, M., and Raina, R. 1995. Epigenetic regulation of the maize Spm transposon. Bioessays 17: 291-297.

Feinberg, A.P. and Vogelstein, B. 1983. A technique for radiolabeling DNA restriction endonuclease fragments to high specific activity. Anal. Biochem. 132: 6-13.

Finnegan, E.J., Peacock, W.J., and Dennis, E.S. 1996. Reduced DNA methylation in Arabidopsis thaliana results in abnormal plant development. Proc. Natl. Acad. Sci. 93: 84498454.

Glazebrook, J. 1999. Genes controlling expression of defense responses in Arabidopsis. Curr. Opin. Plant Biol. 2: 280286.

Greenberg, J.T. 2000. Positive and negative regulation of salicylic acid-dependent cell death and pathogen resistance in Arabidopsis $1 s d 6$ and ssi1 mutants. Mol. Plant Microbe Interact. 13: 877-881.

Hammond-Kosack, K.E. and Jones, J.D. 1996. Resistance genedependent plant defense responses. Plant Cell 8: 1773-1791.

. 1997. Plant disease resistance genes. Annu. Rev. Plant Physiol. Plant Mol. Biol. 48: 575-607.

Haughn, G. and Somerville, C.R. 1987. Selection for herbicide resistance at the whole-plant level. ACS Symp. Ser-Amer. Chem. Soc. 334: 98-107.

Hollick, J.B., Dorweiler, J.E., and Chandler, V.L. 1997. Paramutation and related allelic interactions. Trends Genet. 13: $302-308$.

Irelan, J.T. and Selker, E.U. 1997. Cytosine methylation associated with repeat-induced point mutation causes epigenetic gene silencing in Neurospora crassa. Genetics 146: 509-523.

Jacobsen, S.E. and Meyerowitz, E.M. 1997. Hypermethylated SUPERMAN epigenetic alleles in Arabidopsis. Science 277: 1100-1103.

Jacobsen, S.E., Sakai, H., Finnegan, E.J., Cao, X., and Meyerowitz, E.M. 2000. Ectopic hypermethylation of flower-specific genes in Arabidopsis. Curr. Biol. 10: 179-186.

Jeddeloh, J.A., Bender, J., and Richards, E.J. 1998. The DNA methylation locus DDM1 is required for maintenance of gene silencing in Arabidopsis. Genes \& Dev. 12: 1714-1725.

Jeddeloh, J.A., Stokes, T.L., and Richards, E.J. 1999. Maintenance of genomic methylation requires a SWI2/SNF2-like protein. Nat. Genet. 22: 94-97.

Kakutani, T., Jeddeloh, J.A., Flowers, S.K., Munakata, K., and Richards, E.J. 1996. Developmental abnormalities and epimutations associated with DNA hypomethylation mutations. Proc. Natl. Acad. Sci. 93: 12406-12411.

Kermicle, J.L., Eggleston, W.B., and Alleman, M. 1995. Organization of paramutagenicity in $R$-stippled maize. Genetics 141: 361-372.

Kieber, J.J., Rothenberg, M., Roman, G., Feldmann, K.A., and Ecker, J.R. 1993. CTR1, a negative regulator of the ethylene response pathway in Arabidopsis, encodes a member of the raf family of protein kinases. Cell 72: 427-441.

Koncz, C. and Schell, J. 1986. The promoter of TL-DNA gene 5 controls the tissue-specific expression of chimaeric genes carried by a novel type of Agrobacterium binary vector. Mol. Gen. Genet. 204: 383-396.

Konieczny, A. and Ausubel, F.M. 1993. A procedure for mapping Arabidopsis mutations using co-dominant ecotype-specific 
PCR-based markers. Plant J. 4: 403-410.

Luff, B., Pawlowski, L., and Bender, J. 1999. An inverted repeat triggers cytosine methylation of identical sequences in Arabidopsis. Mol. Cell 3: 505-511.

Maleck, K., Levine, A., Eulgem, T., Morgan, A., Schmid, J., Lawton, K.A., Dangl, J.L., and Dietrich, R.A. 2000. The transcriptome of Arabidopsis thaliana during systemic acquired resistance. Nat. Genet. 26: 403-410.

Martienssen, R. and Baron, A. 1994. Coordinate suppression of mutations caused by Robertson's Mutator transposons in maize. Genetics 136: 1157-1170.

Martienssen, R., Barkan, A., Taylor, W.C., and Freeling, M. 1990. Somatically heritable switches in the DNA modification of $M u$ transposable elements monitored with a suppressible mutant in maize. Genes \& Dev. 4: 331-343.

McClintock, B. 1951. Chromosome organization and genic expression. Cold Spring Harbor Symp. Quant. Biol. 16: 13-47.

Melquist, S., Luff, B., and Bender, J. 1999. Arabidopsis PAI gene arrangements, cytosine methylation and expression. Genetics 153: 401-413.

Meyers, B.C., Dickerman, A.W., Michelmore, R.W., Sivaramakrishnan, S., Sobral, B.W., and Young, N.D. 1999. Plant disease resistance genes encode members of an ancient and diverse protein family within the nucleotide-binding superfamily. Plant J. 20: 317-332.

Michaud, E.J., van Vugt, M.J., Bultman, S.J., Sweet, H.O., Davisson, M.T., and Woychik, R.P. 1994. Differential expression of a new dominant agouti allele (Aiapy) is correlated with methylation state and is influenced by parental lineage. Genes \& Dev. 8: 1463-1472.

Miura, A., Yonebayashi, S., Watanabe, K., Toyama, T., Shimada, H., and Kakutani, T. 2001. Mobilization of transposons by a mutation abolishing full DNA methylation in Arabidopsis. Nature 411: 212-214.

Morgan, H.D., Sutherland, H.G., Martin, D.I., and Whitelaw, E. 1999. Epigenetic inheritance at the agouti locus in the mouse. Nat. Genet. 23: 314-318.

Noël, L., Moores, T.L., van Der Biezen, E.A., Parniske, M., Daniels, M.J., Parker, J.E., and Jones, J.D. 1999. Pronounced intraspecific haplotype divergence at the RPP5 complex disease resistance locus of Arabidopsis. Plant Cell 11: 20992112.

Oldroyd, G.E.D. and Staskawicz, B.J. 1998. Genetically engineered broad-spectrum disease resistance in tomato. Proc. Nat1. Acad. Sci. 95: 10300-10305.

Parker, J.E., Coleman, M.J., Szabo, V., Frost, L.N., Schmidt, R., van der Biezen, E.A., Moores, T., Dean, C., Daniels, M.J., and Jones, J.D. 1997. The Arabidopsis downy mildew resistance gene RPP5 shares similarity to the toll and interleukin-1 receptors with $N$ and L6. Plant Cell 9: 879-894.

Petersen, M., Brodersen, P., Naested, H., Andreasson, E., Lindhart, U., Johansen, B., Nielsen, H.B., Lacy, M., Austin, M.J., Parker, et al. 2000. Arabidopsis map kinase 4 negatively regulates systemic acquired resistance. Cell 103: 1111-1120.

Riggs, A.D. and Jones, P.A. 1983. 5-Methylcytosine, gene regulation, and cancer. Adv. Cancer Res. 40: 1-30.

Ronemus, M.J., Galbiati, M., Ticknor, C., Chen, J., and Dellaporta, S.L. 1996. Demethylation-induced developmental pleiotropy in Arabidopsis. Science 273: 654-657.

Ryals, J., Weymann, K., Lawton, K., Friedrich, L., Ellis, D., Steiner, H.Y., Johnson, J., Delaney, T.P., Jesse, T., Vos, P., et al. 1997. The Arabidopsis NIM1 protein shows homology to the mammalian transcription factor inhibitor $I \kappa B$. Plant Cell 9: 425-439.

Selker, E.U. 1997. Epigenetic phenomena in filamentous fungi: Useful paradigms or repeat-induced confusion? Trends
Genet. 13: 296-301.

Shah, J., Kachroo, P., and Klessig, D.F. 1999. The Arabidopsis ssi1 mutation restores pathogenesis-related gene expression in npr1 plants and renders defensin gene expression salicylic acid dependent. Plant Cell 11: 191-206.

Singer, T., Yordan, C., and Martienssen, R.A. 2001. Robertson's Mutator transposons in $A$. thaliana are regulated by the chromatin-remodeling gene decrease in DNA methylation (DDM1). Genes \& Dev. 15: 591-602.

Soppe, J.W., Jacobsen, E.S., Alonso-Blanco, C., Jackson, P.J., Kakutani, T., Koornneef, M., and Peeters, J.A. 2000. The late flowering phenotype of $f_{w a}$ mutants is caused by gain-offunction epigenetic alleles of a homeodomain gene. Mol. Cell 6: 791-802.

Tang, X., Xie, M., Kim, Y.J., Zhou, J., Klessig, D.F., and Martin, G.B. 1999. Overexpression of Pto activates defense responses and confers broad resistance. Plant Cell 11: 15-29.

Uknes, S., Mauch-Mani, B., Moyer, M., Potter, S., Williams, S., Dincher, S., Chandler, D., Slusarenko, A., Ward, E., and Ryals, J. 1992. Acquired resistance in Arabidopsis. Plant Cell 4: 645-656.

Vongs, A., Kakutani, T., Martienssen, R.A., and Richards, E.J. 1993. Arabidopsis thaliana DNA methylation mutants. Science 260: 1926-1928.

Walker, E.L. 1998. Paramutation of the $r 1$ locus of maize is associated with increased cytosine methylation. Genetics 148: $1973-1981$

Whalen, M.C., Innes, R.W., Bent, A.F., and Staskawicz, B.J. 1991. Identification of Pseudomonas syringae pathogens of Arabidopsis and a bacterial locus determining avirulence on both Arabidopsis and soybean. Plant Cell 3: 49-59.

Wilson, V.L. and Jones, P.A. 1983. Inhibition of DNA methylation by chemical carcinogens in vitro. Cell 32: 239-246.

Xiao, S., Ellwood, S., Calis, O., Patrick, E., Li, T., Coleman, M., and Turner, J.G. 2001. Broad-spectrum mildew resistance in Arabidopsis thaliana mediated by RPW8. Science 291: 118120. 


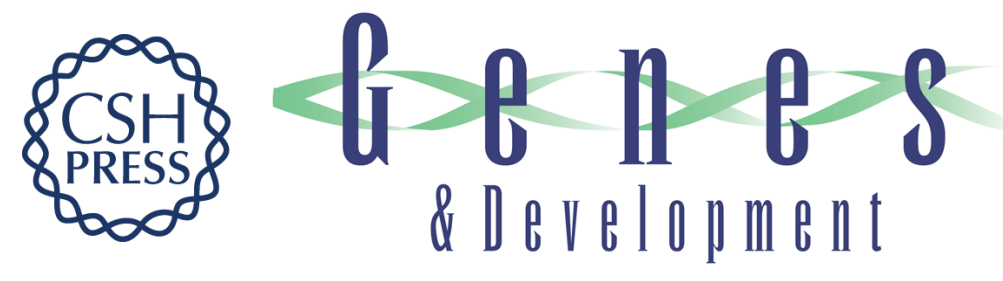

\section{Epigenetic variation in Arabidopsis disease resistance}

Trevor L. Stokes, Barbara N. Kunkel and Eric J. Richards

Genes Dev. 2002, 16:

Access the most recent version at doi:10.1101/gad.952102

References This article cites 65 articles, 33 of which can be accessed free at: http://genesdev.cshlp.org/content/16/2/171.full.html\#ref-list-1

License

Email Alerting Receive free email alerts when new articles cite this article - sign up in the box at the top Service right corner of the article or click here.

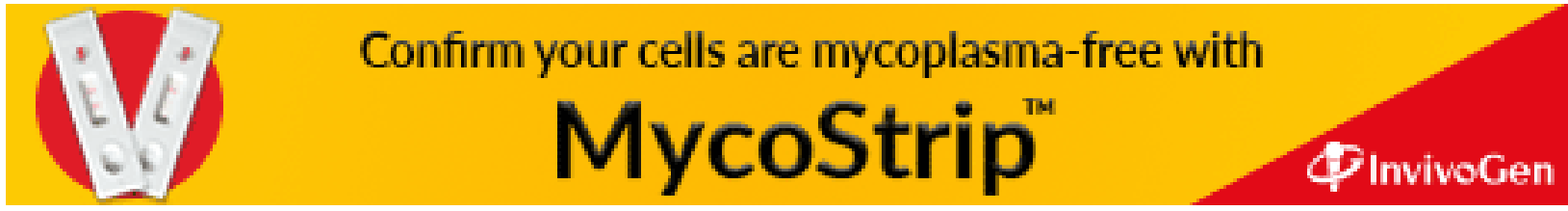

